\title{
O estado do Paraná e o orçamento para o esporte - 2002 a 2018
}

\section{RESUMO}

O estudo tem por objetivo analisar o comportamento do financiamento orçamentário do estado do Paraná no período de 2002 a 2018. Esta pesquisa documental e quantitativa coletou dados orçamentários do governo paranaense da Secretaria do Tesouro Nacional. Foram considerados os recursos empenhados do orçamento estadual e das funções "Desporto e Lazer", "Ciência e Tecnologia", "Segurança Pública", "Assistência Social", "Saúde", "Educação" e "Cultura". Concluímos que o governo paranaense investiu $0,11 \%$ (R\$ 688 milhões) de seu orçamento no esporte e que o comportamento do financiamento esportivo não acompanhou as tendências do orçamento estadual. Marcado por expressivas oscilações, o esporte apresentou um dos menores índices de incrementos entre todas as áreas analisadas e as oscilações aproximam-se do comportamento cíclico eleitoral de investimentos. O "Desporto Comunitário" totalizou o maior volume de recursos, mas incorporou investimentos do "Desporto de Rendimento", o que impossibilita a análise precisa das prioridades adotadas pelo governo estadual.

PALAVRAS-CHAVE: Política pública; Financiamento governamental; Esportes

\section{Suélen Barboza Eiras de Castro}

Doutora em Educação Física Universidade Federal do Paraná, Departamento de Educação Física, Curitiba, Brasil sueleneiras@hotmail.com Ohttps://orcid.org/0000-0001-9728$\underline{8407}$

Ana Paula Cabral Bonin Maoski Doutora em Educação Física Universidade Tecnológica Federal do Paraná, Departamento de Educação Física, Curitiba, Brasil bonin@utfpr.edu.br

๑https://orcid.org/0000-0002-6995$\underline{8634}$

Fernando Marinho Mezzadri Doutor em Educação Física Universidade Federal do Paraná, Departamento de Educação Física, Curitiba, Brasil fmezzadri@uol.com.br https://orcid.org/0000-0001-8601$\underline{5227}$ 


\title{
The state of Paraná and the budget for sport - 2002 to 2018
}

\begin{abstract}
The study aims to analyze the behavior of budget financing in the state of Paraná from 2002 to 2018. This documentary and quantitative research collected data from the Paraná government at the National Treasury Secretariat. We considered the committed resources from the state budget and from the functions "Sports and Leisure", "Science and technology", "Public Security", "Social Assistance", "Health", "Education" and "Culture". We conclude that the government of Paraná invested $0.11 \%(\mathrm{R} \$ 688$ million) of its budget in sports and that the behavior of sports financing did not follow the trends of the state budget. Marked by expressive fluctuations, the sport had one of the lowest rates of increments and the fluctuations are close to the cyclical electoral behavior of investments. "Community Sports" totaled the largest volume of resources, but incorporated investments from "Elite Sports", which makes it impossible to accurately analyze the priorities adopted by the state government.
\end{abstract}

KEYWORDS: Public policy; Government funding; Sports

El estado de Paraná y el presupuesto para el deporte - 2002 a 2018

\section{RESUMEN}

El estudio tiene como objetivo analizar el comportamiento del financiamiento presupuestario en el estado de Paraná de 2002 a 2018. Esta investigación documental y cuantitativa recopiló datos del gobierno de Paraná en la Secretaría del Tesoro Nacional. Fueron considerados los recursos comprometidos del presupuesto estatal y de las funciones "Deporte y ocio", "Ciencia y tecnología", "Seguridad pública", "Asistencia social", "Salud", "Educación" y "Cultura". Concluimos que el gobierno de Paraná invirtió el 0,11\% (R\$ 688 millones) de su presupuesto en deportes y que el comportamiento del financiamiento deportivo no siguió las tendencias del presupuesto estatal. Marcado por fluctuaciones expresivas, el deporte tuvo una de las tasas de incremento más bajas y cómo las fluctuaciones se acercan al comportamiento cíclico electoral de las inversiones. "Deporte Comunitario" totalizó el mayor volumen de recursos, pero incorporó inversiones "Deporte de Élite", lo que imposibilita analizar con precisión las prioridades adoptadas por el gobierno estatal.

PALABRAS-CLAVE: Políticas públicas; Financiación gubernamental; Deportes 


\section{INTRODUÇÃO}

No Brasil, o direito ao esporte é assegurado pela Constituição Federal e por todas as constituições estaduais. De acordo com a legislação brasileira, o sistema nacional do desporto, somado aos sistemas esportivos estaduais, do Distrito Federal e municípios deverão atuar em regime de colaboração com o objetivo de garantir a prática esportiva regular (BRASIL, 1998). Apesar do indicativo de regime de colaboração, as normativas não são claras quanto a atuação dos diferentes entes federativos na promoção das políticas esportivas.

Diferentemente de outras áreas, no setor esportivo não há responsabilidades específicas da União, estados e municípios no que tange a proposição de políticas públicas (TOLEDO, 2014). No Brasil, o esporte não detém competência exclusiva e nem competência comum. Isto é, o esporte não remete a uma responsabilidade intransferível de um dos entes federativos, como também não se configura como uma área que precisa de cooperação entre os entes para a redução de desigualdades (SANTOS; CARVALHO; SOUSA, 2020). Diante da autonomia política e fiscal dos entes, os governos estaduais e municipais podem, por exemplo, estabelecer agendas próprias, independentemente da agenda federal (ARRETCHE, 2004).

A falta de clareza e normatização sobre os níveis e graus de atuação dos entes federativos, bem como das demais entidades envolvidas com a promoção do esporte no Brasil, tem suscitado intensos debates e fomentado a instituição de um sistema nacional para o esporte ${ }^{1}$. Acredita-se que, dentre outras coisas, o sistema nacional poderia organizar as ações das entidades esportivas, sejam elas públicas ou privadas, para otimizar as ações esportivas e estabelecer políticas efetivas, minimizando a sobreposição de ações e/ou a existência de lacunas na oferta do esporte no país.

Além de não indicar o grau de intervenção dos entes federativos, a legislação brasileira atual também não definiu percentuais mínimos de investimentos no setor esportivo a partir do orçamento público. Vale lembrar que, tanto União, quanto estados, Distrito Federal e municípios devem assegurar parte de seus recursos orçamentários para o fomento esportivo (BRASIL, 1998). Os recursos orçamentários, todavia, são considerados como discricionários no setor esportivo. Isto é, não são dotados de obrigatoriedade de execução, ainda que estejam previstos pela Lei Orçamentária Anual (LOA).

\footnotetext{
${ }^{1}$ A integração e definição dos graus de atuação dos entes federativos é um dos objetivos almejados com a proposição do Sistema Nacional do Esporte (SINESP). O SINESP está exposto em projeto de "Lei Geral do Esporte" (PLS 68/2017), o qual tem tramitado no Senado Federal desde 2017. Nesta proposta, o SINESP é compreendido como um sistema descentralizado, democrático e participativo para a gestão e promoção das políticas públicas para o esporte e que tem como um de seus objetivos, "estabelecer as responsabilidades dos entes federativos na estruturação, regulação, manutenção e expansão das atividades e das políticas públicas na área esportiva (BRASIL, 2017).
} 
A garantia de recursos configura-se como um importante elemento para a consecução de uma política pública, pois é através dele que o Estado pode intervir de maneira direta na sociedade estimulando ações ou solucionando problemas (BOTELHO, 2001). A compreensão da destinação dos recursos públicos, consequentemente, se constitui como um importante mecanismo de análise das políticas públicas, uma vez que o financiamento é resultado de uma escolha política que reflete as demandas consideradas como mais importantes pelo governo (ASSIS, 2009). Ou seja, para além dos discursos políticos e documentos oficiais, a maneira como os recursos financeiros são designados para a implementação de ações públicas, seja no esporte ou em qualquer outra área, é um dos principais indicativos das prioridades efetivamente adotadas pelo poder público (TOLEDO, 2014).

No setor esportivo, grande parte das pesquisas relativas ao financiamento público tem abarcado os recursos orçamentários e contemplado a esfera federal (SANTOS; MENDES, 2020). Os estudos sobre o financiamento para o esporte nas demais esferas, estadual e municipal, ainda são incipientes. Considerando a relevância do financiamento enquanto elemento de análise das prioridades tomadas pelo poder público e a pouca produção científica sobre o financiamento estadual, este trabalho tem por objetivo analisar o comportamento do financiamento orçamentário do estado do Paraná no período de 2002 a 2018. Como objetivos específicos, esta pesquisa visa: 1) Investigar a evolução do financiamento da função "Desporto e Lazer" do estado do Paraná de 2002 a 2018; 2) Comparar a evolução do financiamento da função "Desporto e Lazer" com outras áreas governamentais e o orçamento geral do estado do Paraná de 2002 a 2018; 3) Mapear a distribuição do financiamento da função "Desporto e Lazer" do estado do Paraná entre as diferentes subfunções do esporte de 2004 a 2018.

Acreditamos que os resultados deste trabalho podem auxiliar na compreensão do financiamento público para o esporte no cenário regional do Estado brasileiro, bem como subsidiar debates relativos as competências das diferentes esferas federativos. Também acreditamos que a apreensão do financiamento para o esporte no nível estadual pode colaborar com a compreensão da extensão do direito ao esporte e lazer no Brasil (SANTOS; CARVALHO; SOUSA, 2020).

\section{Governos estaduais e o financiamento orçamentário para o esporte no Brasil}

Assim como na esfera federal, não há clareza sobre os graus de atuação dos governos estaduais. De acordo com Santos, Carvalho e Souza (2020), ainda que as constituições estaduais indiquem o compromisso com a agenda esportiva, não há a garantia de percentuais de gastos com 
esporte e indicações precisas sobre a concretização do direito ao esporte em nenhuma das constituintes estaduais.

Vale observar que, a legislação brasileira assegurou que os orçamentos estaduais e do Distrito Federal deverão designar parte de seus recursos em programas governamentais para o fomento esportivo (BRASIL, 1998). Também estão previstos recursos extraorçamentários em legislação, especialmente de loterias, para o fomento esportivo a partir de órgãos estaduais e do Distrito Federal (BRASIL, 2018).

A análise das políticas públicas para o esporte implementadas pelos governos estaduais a partir do exame do financiamento orçamentário ainda é escassa (SANTOS; CARVALHO, SOUZA, 2020; SANTOS; JUCHEM; MADURO, 2021). Entre os poucos estudos relativos ao financiamento orçamentário nas esferas estaduais, destacamos as análises comparativas de Santos, Carvalho e Sousa (2020) e das unidades do Distrito Federal (CARNEIRO; MASCARENHAS, 2013; ATHAYDE; DALMAS, 2018), Minas Gerais (DINIZ; SILVA, 2016), Santa Catarina (FURTADO et al., 2016; MILANI, 2018; QUINAUD; ALMEIDA, 2018; QUINAUD et al., 2018), Bahia (SILVA, 2015) e Paraná (TOLEDO, 2014; MILANI, 2018), Pará (MOREIRA; SILVA, 2020) e Piauí (SANTOS; JUCHEM; MADURO, 2021).

A respeito da unidade do Distrito Federal, Carneiro e Mascarenhas (2013), ao analisarem o direcionamento da política esportiva no período de 2008 a 2011, verificaram que há limitações entre o que está previsto em lei e o que efetivamente é gasto e a priorização do esporte de participação nos gastos. Já Athayde e Dalmas (2018), averiguaram, entre os anos de 2008 a 2014, os gastos com o esporte na secretaria estadual do DF e concluíram que as políticas esportivas do DF se caracterizam pela inexistência de um projeto político e organização programática da área, maior direcionamento de recursos às ações de gestão da secretaria e quebra abrupta de gastos com a prática esportiva, seja do esporte de participação, educacional e de rendimento.

Quedas de investimentos também foram constatados em Santa Catarina e no Paraná. Milani (2018), ao comparar a configuração das despesas públicas para o esporte nos estados do Paraná e Santa Catarina entre os anos de 2011 a 2016, concluiu que em ambos os estados a configuração orçamentária revela um comportamento cíclico de aumento de investimentos no período eleitoral, seguidos de decréscimos nos anos pós-eleitorais. No estado do Paraná, os recursos privilegiaram despesas de infraestrutura e em Santa Catarina os investimentos foram equilibrados entre as diferentes ações dos órgãos responsáveis pelo setor esportivo (MILANI, 2018).

A não centralidade do esporte de rendimento e limitação de recursos para o esporte também foram encontradas no estado do Piauí. Santos, Juchem e Maduro (2020) analisaram a participação do governo piauiense no financiamento do esporte entre 2013 e 2017 e concluíram que, apesar de 
uma execução eficiente dos recursos planejados, o montante destinado ao esporte e lazer está aquém do idealizado pelas conferências nacionais de esporte. Os autores também apontam que, em comparação com a Assistência Social e Cultura, a área do esporte é a mais frágil e menos importante na agenda governamental e que, exceto pelos anos de 2016 e 2017, o esporte de rendimento não teve centralidade nos investimentos estaduais.

Diferentemente dos resultados anteriores, Furtado et al. (2018), Quinaud e Almeida (2018) e Quinaud et al. (2018) indicaram o privilégio de eventos esportivos e do esporte de rendimento no financiamento esportivo no estado de Santa Catarina. Furtado et al. (2016) investigaram a distribuição dos recursos do Fundo Estadual de Incentivo ao Esporte (FUNDESPORTE/SC) nos anos de 2011 e 2012 e concluíram que a maior parte dos fundos foi destinada a projetos voltados ao esporte de alto rendimento e a realização de eventos esportivos de grande porte. Ainda sobre o FUNDESPORTE, Quinaud e Almeida (2018), ao analisarem os repasses do fundo para a mesorregião Grande Florianópolis no período de 2007 a 2014, verificaram o privilégio desta região em comparação aos números populacionais e econômicos no estado e o maior repasse de recursos para atletas ou equipes, infraestrutura e eventos. Em estudo semelhante, Quinaud et al. (2018) caracterizaram as demandas e os recursos financeiros do FUNDESPORTE/SC de 2007 a 2014 e concluíram que houve redução na distribuição de recursos públicos e elevada destinação para ações de infraestrutura, realização de eventos e programas focados nos atletas e equipes do esporte de rendimento.

O privilégio do esporte de rendimento também foi verificado no estado do Pará. De acordo com Moreira e Silva (2020), ao investigar a priorização das dimensões esportivas que foram executadas pelo governo estadual do Pará de 2011 a 2014, o esporte de rendimento foi aquele que recebeu o maior investimento no período. Ainda de acordo com os autores, houve um investimento crescente de ações voltadas ao esporte de rendimento, a partir da "realização dos projetos de grandes eventos esportivos no Estado, com a parceria de empresas estatais federais [...], bem como apoio às entidades esportivas, como federações e clubes esportivos, além do investimento nas bolsas-atletas" (MOREIRA; SILVA, 2020, p. 18).

$\mathrm{Na}$ Bahia, Silva (2015) investigou o planejamento e a execução orçamentária das políticas estaduais de lazer e concluiu que, enquanto o planejamento do governo estadual elenca o lazer enquanto ferramenta de inclusão social, o financiamento foi direcionado à ações pontuais, de caráter focalista e com abrangência limitada. Em Minas Gerais, Diniz e Silva (2016) discutiram a função do ICMS Esportivo, o qual é vinculado à Secretaria Estadual de Esportes/MG, no que tange ao financiamento das políticas esportivas de 2011 a 2014, e constataram a expressiva valorização dos eventos municipais esportivos. 
$\mathrm{Na}$ análise comparativa entre os estados brasileiros, Santos, Carvalho e Sousa (2020) avaliaram a participação dos governos estaduais no financiamento do esporte entre 2002 a 2016 a fim de verificar se a autonomia destes entes federativos produz equidade ou desigualdade na oferta de políticas esportivas. De acordo com os autores, nos estados de maior desenvolvimento econômico, o padrão de financiamento para o esporte não seguiu a produção de desigualdade do Produto Interno Bruto (PIB), e nos estados de menor desenvolvimento econômico, o padrão de financiamento para o esporte não foi afetado pelo Fundo de Participação dos Estados e Distrito Federal (FPE) e não teve efeito redistributivo (SANTOS; CARVALHO; SOUSA, 2020).

\section{O Paraná e a política esportiva}

No Paraná, e assim como na esfera federal, a intervenção estatal no esporte antecede o reconhecimento do dever do Estado no fomento das práticas esportivas no Brasil. O início da atuação governamental no setor esportivo data a década de 1950, quando, sob a gestão de Bento Munhoz da Rocha (1951-1956), clubes e associações que desenvolviam práticas esportivas passaram a ser financiadas pelo governo paranaense (TOLEDO, 2014). Ainda na década de 1950, o estado paranaense, sob gestão de Moysés Lupion (1956-1961), passou a adotar uma política de realização de eventos esportivos. Em 1957 foi instaurado os Jogos Abertos do Paraná e, posteriormente, os Jogos Escolares e os Jogos Universitários. A política esportiva paranaense, portanto, surge e se consolida ao longo dos anos 1950 a partir do financiamento de entes esportivos privados e da realização de eventos esportivos. Este modelo permaneceu inalterado ao longo das décadas de 1960 e 1970 (TOLEDO, 2014).

No quadro legal, as mudanças tornaram-se mais marcantes quando, com o advento da Constituição Federal de 1988, a estrutura jurídica e institucional do estado paranaense passou por ajustes. Em 05 de outubro de 1989, foi instituída a Constituição do Estado do Paraná, e parte dos dispositivos que tratam do esporte na Constituição Federal de 1988 foram acolhidos integralmente pela legislação paranaense (TOLEDO, 2014). De acordo com a Constituição do Paraná,

Art. 197. É dever do Estado fomentar as atividades desportivas em todas as suas manifestações, como direito de cada um, assegurando:

I - autonomia das entidades desportivas e associações, quanto à organização e funcionamento;

II - destinação de recursos públicos para a promoção prioritária do esporte educacional e amador;

III - incentivo a programas de capacitação de recursos humanos, à pesquisa e ao desenvolvimento científico aplicado à atividade esportiva;

IV - criação de medidas de apoio e valorização do talento desportivo; 
V - estímulo à construção, manutenção e aproveitamento de instalações e equipamentos desportivos e destinação de área para atividades desportivas, nos projetos de urbanização pública, habitacionais e nas construções escolares;

VI - tratamento diferenciado para o desporto profissional e não profissional;

VII - equipamentos e instalações adequados à prática de atividades físicas e desportivas pelos portadores de deficiência.

Art. 198. Caberá ao Estado estabelecer e desenvolver planos e programas de construções e instalações desportivas comunitárias para a prática do desporto popular.

Art. 199. O Poder Público incentivará o lazer, como forma de promoção social. (PARANÁ, 1989).

Ainda que a legislação tenha incluído em seus dispositivos ações como a construção de equipamentos públicos para a prática esportiva, o modelo histórico de atuação do governo paranaense prosseguiu com a organização de eventos esportivos (TOLEDO, 2014). Também é possível observar relativa continuidade na estrutura organizacional do estado do Paraná no que tange as políticas esportivas. Desde 1995, dois órgãos têm protagonizado a formulação e implementação de políticas para o esporte no Paraná: 1) Paraná Esporte, posteriormente denominada de Instituto Paranaense de Ciência do Esporte (IPCE) ${ }^{2}$; e 2) Conselho Estadual de Esporte e Lazer (CEEL) ${ }^{3}$. Ambos os órgãos, ainda que tenham transitado em diferentes instituições, não sofreram mudanças expressivas nos papéis desempenhados (TOLEDO, 2014).

Atualmente, o IPCE encontra-se vinculado à Secretaria de Estado da Educação e do Esporte (SEED) e o CEEL suspenso". O governo estadual lançou em 2018 a sua "Política de Esporte do Paraná”, o qual tem por objetivo, “a) sensibilizar as pessoas para a importância da prática do esporte ao longo de toda sua vida, assegurando-lhes as oportunidades e condições de acesso; b) incentivar e oportunizar o desenvolvimento dos talentos esportivos” (PARANÁ, 2018, p. 114).

Vale observar que, tal como instituído pela normativa federal, o governo paranaense deve designar parte de seus recursos orçamentários em programas de trabalho constantes para o fomento esportivo. A normativa federal também assegurou a possibilidade de outras fontes extraorçamentárias para a promoção do esporte como um direito de cada um (BRASIL, 1998).

No estado do Paraná, em 2006, por meio da Lei no 15.264, foi instituído o "Programa Estadual de Fomento e Incentivo ao Esporte Amador, Olímpico e Para-Olímpico”. O programa tem

\footnotetext{
${ }^{2}$ Criada em 1995, a Paraná Esporte foi uma autarquia vinculada à SEET que tinha como função a execução de políticas esportivas no estado (PARANÁ, 1995). Em 2011, a partir da Lei no 17.014, a Paraná Esporte passou a denominar-se como Instituto Paranaense de Ciência do Esporte (IPCE) e ter como responsabilidade a execução de ações científicas esportivas, a deteç̧ão de talentos esportivos e de atletas de alto rendimento (PARANÁ, 2011).

${ }^{3}$ Instituído em 1995, a partir do Decreto $\mathrm{n}^{\circ}$ 702, o Conselho Estadual de Esporte e Lazer foi vinculado, inicialmente, à Secretaria de Estado do Esporte e Turismo (SEET), e atuava como órgão normativo, consultivo e deliberativo do Sistema Estadual de Desenvolvimento do Esporte e Lazer e representativo da comunidade esportiva paranaense (PARANÁ, 1995).

${ }^{4} \mathrm{Em} 2020$, o Decreto $\mathrm{n}^{\circ} 4168$ revogou diversas normativas anteriores, incluindo aquele que regulamentava a atuação do CEEL no Paraná.
} 
por objetivo incentivar o esporte amador no estado paranaense e assegura a possibilidade de abatimento de ICMS de empresas que apoiarem financeiramente entidades de administração do esporte, atletas, equipes, profissionais e projetos esportivos. O programa também conta com recursos provenientes do orçamento do estado, bem como de fundos, doações, patrocínios, legados, concursos de prognósticos, incentivos fiscais, entre outros (PARANÁ, 2006).

Em 2017, o governo estadual também instituiu o "Programa Estadual de Fomento e Incentivo ao Esporte - PROESPORTE" a partir do Decreto $\mathrm{n}^{\circ}$ 8560. Este programa tem por objetivos, "I - incentivar o esporte; II - facilitar à comunidade as oportunidades e condições de acesso ao esporte; III - estimular o desenvolvimento esportivo em todas as regiões do Estado; IV fomentar a pesquisa nas diversas áreas do esporte” (PARANÁ, 2017). Para isso, a ação prevê recursos orçamentários e de incentivos fiscais, transferências da União, subvenções de entidades públicas e privadas, doações, legados, saldos remanescentes, juros, multas e devoluções, entre outros (PARANÁ, 2017).

Foram poucos os estudos que analisaram o financiamento púbico do esporte no estado do Paraná. Encontramos apenas dois: Toledo (2014) e Milani (2018). Toledo (2014) investigou a relação entre a concepção do esporte como um direito social e as políticas efetivadas no setor esportivo entre os anos de 1995 e 2010. A autora verificou uma tendência, ainda que não uniforme, de queda da dotação orçamentária para o esporte, e concluiu que o percentual para o setor, em comparação com o orçamento geral do estado, é significativamente baixo, não ultrapassando 0,4\% das despesas fixadas. Toledo (2014) também concluiu que, independentemente das divergências políticas dos governos analisados, aproximadamente $90 \%$ dos recursos orçamentários é destinado à organização de eventos esportivos, o que remete a própria trajetória histórica das políticas paranaenses.

O trabalho de Milani (2018), contudo, aponta outros resultados. A autora investigou a produção legislativa e a distribuição dos recursos públicos para o esporte no estado entre os anos de 2003 a 2017 e concluiu que o financiamento esportivo não se configura como foco de preocupação dos parlamentares e que não é possível atestar uma conclusão derradeira sobre os objetivos e prioridades das gestões do período analisado. A autora, contudo, atesta que os projetos de lei com maior número de proposições na Assembleia Legislativa do estado eram aquelas relacionadas com infraestrutura esportiva. Milani (2018) também verificou que a configuração orçamentária revela um comportamento cíclico de aumento de investimentos no período eleitoral, seguidos de decréscimos nos anos pós-eleitorais. 


\section{METODOLOGIA}

Este estudo se caracteriza como uma pesquisa documental de natureza quantitativa que tem por objetivo analisar o comportamento do financiamento orçamentário do estado do Paraná no período de 2002 a 2018. Os dados orçamentários do governo estadual do Paraná foram coletados do portal da Secretaria do Tesouro Nacional por meio do Siconfi ${ }^{5}$. Esta coleta considerou os recursos orçamentários empenhados da função " 27 - Desporto e Lazer” e os valores de suas respectivas subfunções: "27.122 - Administração Geral”, "27.811 - Desporto de Rendimento”, "27.812 Desporto Comunitário", “27.813 - Lazer”, e "Demais subfunções”.

Também coletamos o somatório dos recursos empenhados de todas as funções orçamentárias do estado do Paraná e, a título de comparação, os dados das funções: 06 - Segurança Pública, 08 Assistência Social, 10 - Saúde, 12 - Educação, 13 - Cultura, 14 - Direitos da Cidadania e 19 Ciência e Tecnologia. A opção pelo recorte temporal de 2002 a 2018 se deu pela disponibilização da totalidade dos dados durante o período de coleta dos dados ( $2^{\circ}$. semestre de 2019).

Todos os dados foram tabulados no Microsoft Office Excel e deflacionados de acordo com o índice do IPCA ${ }^{7}$ para 2018. Em seguida, calculamos índices de investimentos tomando como base o ano inicial do período, fazendo com que os valores de todas as funções fossem iguais a 100 (cem) no ano de início das séries (2002). O cálculo foi realizado da seguinte forma: Índice $\mathrm{Anol}=\left(\right.$ Valor $_{\mathrm{Ano1}}$ $\mathrm{x}$ 100) / Valor $_{\text {Ano. }}$ Deste modo, independente do porte dos orçamentos das diferentes áreas governamentais, todas elas tomariam como ponto de partida o mesmo índice de investimento, possibilitando analisar a sua evolução no decorrer dos anos a partir da comparação do ponto inicial. Nossa intenção com esta proposta de análise foi a de estabelecer um padrão comparativo da evolução dos investimentos independentemente do seu volume orçamentário.

\section{RESULTADOS E DISCUSSÃO}

O estado do Paraná investiu um total de R\$ 688 milhões na função "Desporto e Lazer”, o que correspondeu a $0,11 \%$ do orçamento total do estado paranaense no período de 2002 a 2018 . No decorrer do período, os investimentos para o esporte apresentaram expressiva variação, ora para mais, ora para menos. Já o orçamento estadual, que totalizou R\$ 628 bilhões, exceto por 2015 e

${ }^{5}$ Sistema de Informações Contábeis e Fiscais do Setor Público Brasileiro. Disponível em: https://siconfi.tesouro.gov.br/siconfi/index.jsf

${ }^{6}$ Desde a publicação da Portaria $\mathrm{n}^{\circ} 42$ de 14 de abril de 1999, a União estabeleceu regras comuns para detalhar as despesas orçamentárias por função. Compreendida como o maior nível de agregação das diversas áreas de despesas públicas, a função é o componente da política físcal que tem sido utilizada pelos três entes federados para dimensionar seus gastos de acordo com as áreas de atuação governamental.

${ }^{7}$ Considerado o índice oficial de inflação do país, o IPCA - Índice Nacional de Preços ao Consumidor Amplo -, é medido mensalmente pelo IBGE e o mesmo abrange as famílias com rendimentos mensais compreendidos entre 1 e 40 salários-mínimos, qualquer que seja a fonte de rendimentos, e residentes nas áreas urbanas das regiões (IBGE, 2017). 
2018, apresentou um quadro de pequenos incrementos ao longo dos anos. Deste modo, enquanto o orçamento paranaense aponta para um quadro de estabilidade em sua capacidade financeira, o orçamento esportivo paranaense apresenta um padrão de instabilidade em seus investimentos e de relativa independência do comportamento do orçamento estadual.

Tabela 1 - Recursos empenhados na função "Desporto e Lazer” e orçamento do estado do Paraná de 2002 a 2018

\begin{tabular}{|c|c|c|c|c|c|c|}
\hline \multicolumn{5}{|c|}{ Desporto e Lazer } & \multicolumn{2}{|l|}{ Orçamento Geral } \\
\hline $\begin{array}{c}\text { An } \\
\mathbf{0}\end{array}$ & $\mathbf{R S}$ & Percapita & $\begin{array}{l}\text { \% Orç. } \\
\text { PR }\end{array}$ & $\begin{array}{c}\% \mathrm{Va} \\
\mathbf{r}\end{array}$ & $\mathbf{R S}$ & $\%$ Var \\
\hline $\begin{array}{c}200 \\
2\end{array}$ & $\begin{array}{c}\mathrm{R} \$ \\
28.398 .297,72\end{array}$ & $\begin{array}{r}\mathrm{R} \$ \\
2,72\end{array}$ & $0,12 \%$ & 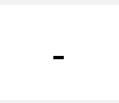 & $\begin{array}{c}\mathrm{R} \$ \\
24.579 .591 .777,90\end{array}$ & - \\
\hline $\begin{array}{c}200 \\
3\end{array}$ & $\begin{array}{c}\mathrm{R} \$ \\
17.086 .148,03\end{array}$ & $\begin{array}{r}\mathrm{R} \$ \\
1,64\end{array}$ & $0,07 \%$ & $-40 \%$ & $\begin{array}{c}\mathrm{R} \$ \\
24.717 .054 .806,57\end{array}$ & $+0,6 \%$ \\
\hline $\begin{array}{c}200 \\
4\end{array}$ & $\begin{array}{c}\mathrm{R} \$ \\
10.912 .235,11\end{array}$ & $\begin{array}{r}\mathrm{R} \$ \\
1,04\end{array}$ & $0,04 \%$ & $-36 \%$ & $\begin{array}{c}\mathrm{R} \$ \\
25.271 .819 .440,96\end{array}$ & $+2,2 \%$ \\
\hline $\begin{array}{c}200 \\
5\end{array}$ & $\begin{array}{c}\mathrm{R} \$ \\
20.726 .543,81\end{array}$ & $\begin{array}{r}\mathrm{R} \$ \\
1,98\end{array}$ & $0,08 \%$ & $+90 \%$ & $\begin{array}{c}\mathrm{R} \$ \\
27.257 .719 .770,40\end{array}$ & $+7,9 \%$ \\
\hline $\begin{array}{c}200 \\
6\end{array}$ & $\begin{array}{c}\mathrm{R} \$ \\
24.851 .752,01\end{array}$ & $\begin{array}{r}\mathrm{R} \$ \\
2,38\end{array}$ & $0,09 \%$ & $+20 \%$ & $\begin{array}{c}\mathrm{R} \$ \\
29.219 .279 .581,79\end{array}$ & $+7,2 \%$ \\
\hline $\begin{array}{c}200 \\
7\end{array}$ & $\begin{array}{c}\mathrm{R} \$ \\
20.688 .110,59\end{array}$ & $\begin{array}{r}\mathrm{R} \$ \\
1,98\end{array}$ & $0,07 \%$ & $-17 \%$ & $\begin{array}{c}\mathrm{R} \$ \\
29.791 .704 .451,40\end{array}$ & $+2,0 \%$ \\
\hline $\begin{array}{c}200 \\
8\end{array}$ & $\begin{array}{c}\mathrm{R} \$ \\
19.551 .030,44\end{array}$ & $\begin{array}{r}\mathrm{R} \$ \\
1,87\end{array}$ & $0,06 \%$ & $-5 \%$ & $\begin{array}{c}\mathrm{R} \$ \\
32.319 .138 .380,46\end{array}$ & $+8,5 \%$ \\
\hline $\begin{array}{c}200 \\
9\end{array}$ & $\begin{array}{c}\mathrm{R} \$ \\
19.399 .821,47\end{array}$ & $\begin{array}{r}\mathrm{R} \$ \\
1,86\end{array}$ & $0,06 \%$ & $-1 \%$ & $\begin{array}{c}\mathrm{R} \$ \\
33.295 .546 .433,73\end{array}$ & $+3,0 \%$ \\
\hline $\begin{array}{c}201 \\
0\end{array}$ & $\begin{array}{c}\mathrm{R} \$ \\
29.488 .514,81\end{array}$ & $\begin{array}{r}\mathrm{R} \$ \\
2,82\end{array}$ & $0,08 \%$ & $+52 \%$ & $\begin{array}{c}\mathrm{R} \$ \\
35.396 .876 .993,16\end{array}$ & $+6,3 \%$ \\
\hline $\begin{array}{c}201 \\
1\end{array}$ & $\begin{array}{c}\mathrm{R} \$ \\
18.598 .997,81\end{array}$ & $\begin{array}{r}\mathrm{R} \$ \\
1,78\end{array}$ & $0,05 \%$ & $-37 \%$ & $\begin{array}{c}\mathrm{R} \$ \\
36.863 .203 .661,32\end{array}$ & $+4,1 \%$ \\
\hline $\begin{array}{c}201 \\
2\end{array}$ & $\begin{array}{c}\mathrm{R} \$ \\
45.387 .216,67\end{array}$ & $\begin{array}{r}\mathrm{R} \$ \\
4,35\end{array}$ & $0,11 \%$ & $\begin{array}{c}+144 \\
\%\end{array}$ & $\begin{array}{c}\mathrm{R} \$ \\
40.342 .149 .627,45\end{array}$ & $+9,4 \%$ \\
\hline $\begin{array}{c}201 \\
3\end{array}$ & $\begin{array}{c}\mathrm{R} \$ \\
38.024 .404,63\end{array}$ & $\begin{array}{r}\mathrm{R} \$ \\
3,64\end{array}$ & $0,09 \%$ & $-16 \%$ & $\begin{array}{c}\mathrm{R} \$ \\
42.845 .657 .071,63\end{array}$ & $+6,2 \%$ \\
\hline $\begin{array}{c}201 \\
4\end{array}$ & $\begin{array}{c}\mathrm{R} \$ \\
48.914 .007,36\end{array}$ & $\begin{array}{r}\mathrm{R} \$ \\
4,68\end{array}$ & $0,11 \%$ & $+29 \%$ & $\begin{array}{c}\mathrm{R} \$ \\
43.858 .908 .713,21\end{array}$ & $+2,4 \%$ \\
\hline $\begin{array}{c}201 \\
5\end{array}$ & $\begin{array}{c}\mathrm{R} \$ \\
37.854 .427,00\end{array}$ & $\begin{array}{r}\mathrm{R} \$ \\
3,62\end{array}$ & $0,09 \%$ & $-23 \%$ & $\begin{array}{c}\mathrm{R} \$ \\
41.341 .400 .646,48\end{array}$ & $-5,7 \%$ \\
\hline $\begin{array}{c}201 \\
6\end{array}$ & $\begin{array}{c}\mathrm{R} \$ \\
61.445 .454,03\end{array}$ & $\begin{array}{r}\mathrm{R} \$ \\
5,88\end{array}$ & $0,11 \%$ & $+62 \%$ & $\begin{array}{c}\mathrm{R} \$ \\
54.820 .227 .533,29\end{array}$ & $\begin{array}{c}+32,6 \\
\%\end{array}$ \\
\hline $\begin{array}{c}201 \\
7\end{array}$ & $\begin{array}{c}\mathrm{R} \$ \\
154.751 .590,60\end{array}$ & $\begin{array}{c}\mathrm{R} \$ \\
14,82\end{array}$ & $0,27 \%$ & $\begin{array}{c}+152 \\
\%\end{array}$ & $\begin{array}{c}\mathrm{R} \$ \\
57.616 .943 .075,04\end{array}$ & $+5,1 \%$ \\
\hline $\begin{array}{c}201 \\
8\end{array}$ & $\begin{array}{c}\mathrm{R} \$ \\
92.121 .562,26\end{array}$ & $\begin{array}{c}\mathrm{R} \$ \\
8,82\end{array}$ & $0,19 \%$ & $-40 \%$ & $\begin{array}{c}\mathrm{R} \$ \\
49.328 .333 .875,06\end{array}$ & $-\overline{-}$ \\
\hline & $\begin{array}{c}\mathrm{R} \$ \\
688.200 .114,35\end{array}$ & $\begin{array}{r}\mathrm{RS} \\
65,89\end{array}$ & $0,11 \%$ & & $\begin{array}{c}\mathrm{RS} \\
\mathbf{6 2 8 . 8 6 5 . 5 5 5 . 8 3 9 , 8 5}\end{array}$ & \\
\hline
\end{tabular}


Os investimentos em esporte e lazer no estado do Paraná também apontam para relativa independência do comportamento médio dos estados brasileiros. De acordo com Carneiro, Mascarenhas e Athayde (2021), os gastos estaduais na função "Desporto e Lazer" apresentaram uma tendência descendente e concentraram em 2013 e 2014, em decorrência da realização da Copa do Mundo de Futebol 2014, a maior parte dos investimentos realizados no período. Os autores indicaram, por exemplo, que em 2013 foi investido 44\% de todo o volume de recursos orçamentários dos estados brasileiros de 2013 a 2017. Este comportamento diverge da realidade encontrada no estado do Paraná. Por outro lado, o investimento contínuo e a expressiva variação de recursos executados encontrados neste estudo foram consoantes aos achados de Carneiro, Mascarenhas e Athayde (2021).

No que tange as variações do orçamento esportivo paranaense, vale destacar os acréscimos expressivos em 2005, 2012 e 2017. Em 2005, houve o início de alocação orçamentária em outras subfunções, as quais não são detalhadas no orçamento público (“Demais Subfunções”), o que resultou no crescimento do orçamento da área (TABELA 1). Acreditamos que estes gastos estavam relacionados a administração da pasta governamental, uma vez que a partir de 2016, com a instituição da subfunção "Administração Geral” no orçamento público, estas despesas foram zeradas. Este acréscimo em 2005 também foi indicado no estudo de Toledo (2014) e Milani (2018).

Os significativos acréscimos de 2012 e 2017, conforme veremos a seguir, foram decorrentes de aumentos de recursos na subfunção "Desporto Comunitário". Vale observar que esta subfunção se configura como aquela que recebe o maior volume de emendas parlamentares no orçamento esportivo, uma vez que abarca as ações de construção e reforma de espaços e equipamentos de esporte e lazer. Tal como destacado por Fernandes (2012) e Fonseca et al. (2015), a execução de pequenas obras são percebidas como de grande apelo popular e retorno político-eleitoral. Sendo assim, o orçamento pode, em 2012 e 2017, ter somado um grande volume de recursos orçamentários a partir de emendas parlamentares, seja dos representantes da própria esfera federativa, ou da esfera federal, a partir de emendas direcionadas ao estado pelos representantes paranaenses no Congresso Nacional.

O aumento em 2012 também pode estar relacionado a mudanças na estrutura política e administrativa do estado do Paraná. De 2003 a 2010, o Paraná foi governado por Roberto Requião (PMDB) e em 2011 foi substituído por seu oponente Carlos Aberto Richa (PSDB), o qual instituiu mudanças na estrutura administrativa do estado. No que tange ao esporte, em 16 de dezembro de 2011, a partir da Lei n 17.014, foi instituída a Secretaria de Estado do Esporte (SEES) e a Paraná Esporte, entidade autárquica vinculada ao órgão, passou a denominar Instituto Paranaense de 
Ciência do Esporte (IPCE). O ano de 2012 marca a primeira execução do orçamento da nova gestão e o primeiro ano do esporte como objeto único de uma secretaria.

As oscilações encontradas neste estudo divergem da queda de investimentos encontrada por Toledo (2014) e Milani (2018) e se aproximam da hipótese de comportamento cíclico levantada por Milani (2018). No caso da queda, ainda que os dados não assegurem um padrão constante de acréscimos, há uma tendência de aumento nos investimentos da função "Desporto e Lazer" quando analisamos o percurso dos anos investigados. Especialmente a partir de 2012, quando houve mudanças políticas e administrativas, podemos inferir que o valor real e o percentual do orçamento estadual destinado ao esporte elevaram-se, diferenciando-se do período que antecede 2012.

Quanto ao comportamento cíclico, Milani (2018) identificou um aumento de investimentos no período eleitoral, seguidos de decréscimos nos anos pós-eleitorais. Em nosso estudo, exceto por 2009, 2012, 2013, 2016 e 2018, os investimentos, tal como identificado por Milani (2018), seguiram o comportamento de aumento nos períodos pré-eleitorais e eleitorais, e de quedas nos anos pós-eleitorais.

Segundo Orais et al. (2014), a existência de comportamentos cíclicos nos investimentos públicos tem sido abordada por diferentes correntes da economia. Estas correntes têm explorado as relações entre economia e política com o intuito de oferecer explicações adicionais para as flutuações econômicas a partir de fatores políticos ${ }^{8}$, como, por exemplo, os ciclos políticos eleitorais. A hipótese é de que a trajetória temporal dos calendários eleitorais coincide com a existência de componentes cíclicos no investimento público. De maneira geral, percebe-se uma aceleração e aumento das despesas públicas no período pré-eleitoral e uma desaceleração e queda no período pós-eleitoral. Este comportamento cíclico de investimento foi identificado nas três esferas federativas do Brasil (ORAIS et al., 2014) e identificado neste estudo em questão.

A hipótese de que as flutuações das depesas possam ser influenciadas pelo ciclo eleitoral brasileiro, no entanto, não é consenso entre os trabalhos sobre o orçamento esportivo dos entes federativos. O estudo de Santos (2019), por exemplo, investigou a evolução dos investimentos em esporte e lazer entre 2002 a 2016 de municípios da região sul e sudeste sob a ótica da teoria dos ciclos políticos eleitoriais. O autor concluiu que, apesar da maior margem para alterações na composição orçamentária do esporte e lazer, a influência de fatores políticos no espaço orçamentário da área é baixa. Para o autor, "a variação no tempo de adesão e no volume do gasto sugere um comportamento aleatório" (SANTOS, 2019, p. 52).

${ }^{8}$ Sob a titulação de "Ciclos Políticos de Negócios", os estudos dividem-se entre modelos ideológicos e de ciclos eleitorais. Entre os autores, destacam-se os trabalhos pioneiros de Kalecki (1943), e Nordhaus (1975) e Rogoff (1990) (ORAIS et al. 2014). 
A imprecisão dos fatores que afetam o comportamento dos gastos em esporte e lazer pelos entes federativos sugere a necessidade de mais estudos para elucidar esta questão. De maneira geral, há um consenso nos estudos sobre o financiamento orçamentário dos entes federativos que, apesar de inexistir obrigações e atribuições específicas para a implementação de políticas na área do esporte, estes, em sua grande maioria, investem em esporte e lazer. Ou seja, a não atribuição de competências não sugere a inação dos entes (CARNEIRO, MASCARENHAS, ATHAYDE, 2021). A quantidade e qualidade deste gasto, bem como os fatores que influenciam estes investimentos, no entanto, precisam ser melhor elucidados.

No que tange a quantidade do gasto em esporte e lazer, a representatividade do orçamento esportivo frente ao orçamento estadual no Paraná está aquém do que foi reivindicado nas Conferências Nacionais do Esporte (CNE) em 2004, 2006 e 2010. Na primeira e segunda CNE, houve a proposição de que os estados brasileiros garantissem um investimento mínimo de $1 \%$ de seu orçamento para o esporte (BRASIL, 2004; 2006). Já em 2010, na terceira CNE, a proposição passou a ser de 1,5\% do orçamento estadual (BRASIL, 2010). Estas proposições, segundo Carneiro, Mascarenhas e Athayde (2021), atestam a centralidade que o orçamento público tem na efetivação das políticas públicas para o esporte e lazer. A garantia de percentual mínimo de investimentos, todavia, não foi regulamentada e os estudos têm indicado que este percentual está distante da realidade orçamentária do esporte no Brasil.

Os estudos de Toledo (2014) e Milani (2018) também verificaram a baixa representatividade do esporte no orçamento paranaense. De acordo com Toledo (2014), o percentual para o esporte fixado na Lei Orçamentária Anual (LOA) do estado do Paraná entre os anos de 1995 e 2010 não superou $0,4 \%$ do orçamento estadual. Já Milani (2018) identificou que, entre 2003 e 2017, a participação do esporte no orçamento geral do estado não ultrapassou $0,15 \%$. A baixa representatividade também foi verificada no estado do Piaú. De acordo com Santos e Juchem (2021), os orçamentos para o esporte variaram entre $0,08 \%$ e $0,28 \%$ do orçamento estadual investigado.

O pequeno percentual de investimentos paranaenses na área do esporte pode, segundo Toledo (2014), estar relacionado a três aspectos: 1) o crescente volume de despesas obrigatórias, o que limita os investimentos discricionários; 2) a não vinculação dos recursos orçamentários para o esporte; e 3) a ausência de atribuições dos entes federativos no que tange ao esporte. Estes aspectos também foram discutidos em estudos relativos ao orçamento esportivo no nível federal (ATHAYDE; MASCARENHAS, SALVADOR, 2015; CASTRO, 2016).

O debate relativo à regulamentação de gastos obrigatórios não é exclusivo da área esportiva. Este debate, por exemplo, tangencia a própria discussão sobre a natureza jurídica do orçamento 
público brasileiro, se autorizativo ou impositivo. No que tange à implantação do orçamento impositivo, acredita-se que há a garantia efetiva de entrega de bens e serviços à sociedade, bem como a elaboração de projetos mais adequados. A discricionariedade tem sido criticada por se configurar como uma "moeda de troca" para a aquisição de apoio político (SOUZA; XAVIER; ARRUDA, 2020). Por outro lado, a adoção do orçamento impositivo agrava ainda mais a rigidez do orçamento público brasileiro, estabelecendo uma inércia burocrática-orçamentária o que dificulta o reordenamento e a racionalização do gasto público e a autonomia do setor público. Neste sistema, ficam reduzidas as possibilidades de redirecionar a intervenção do Estado e enfrentar, de maneira mais eficaz e aguda, problemas e crises emergentes (MENEZES; PEDERIVA, 2015).

Atualmente, aproximadamente $10 \%$ das despesas orçamentárias são discricionárias e estão sujeitas ao mecanismo de contingenciamento. Conforme já atestado por estudos anteriores, o contingenciamento impacta de maneira negativa a implementação das políticas na área esportiva (ATHAYDE; MASCARENHAS; SALVADOR, 2015; CASTRO, 2016). Sem a imposição orçamentária, seja para gastos obrigatórios em esporte e lazer e nas demais áreas sem obrigatoriedade de investimentos e percentuais mínimos, as despesas e, consequentemente a política pública fica dependente das decisões discricionárias dos governos ou das imposições efetuadas por seus legislativos (SANTOS, 2019). O impacto da obrigatoriedade de investimentos ou não entre as diferentes áreas de atuação governamental pode ser observada a seguir.

Ao compararmos o investimento esportivo com outras áreas de atuação governamental e o orçamento estadual, observamos que até 2011, exceto por 2005 e 2006, a evolução de investimentos da área esportiva esteve abaixo de todas as demais categorias. Ou seja, independentemente do volume de recursos de cada uma das áreas, o orçamento esportivo foi o que deteve um dos menores percentuais de incremento até 2011. A partir de 2012 e nos anos subsequentes, a área supera incrementos de áreas como Ciência e Tecnologia, Cultura, Direitos da Cidadania e Assistência Social e, excepcionalmente em 2017, o investimento no esporte é expressivamente maior que os anos anteriores e as tendências de todas as demais áreas (GRÁFICO 1). Esta mudança de comportamento, maior incremento no esporte e menor incremento nas áreas citadas, pode estar relacionada com as mudanças políticas e administrativas que ocorreram no governo estadual a partir de 2012 .

Gráfico 1 - Evolução do investimento em áreas governamentais do estado do Paraná 


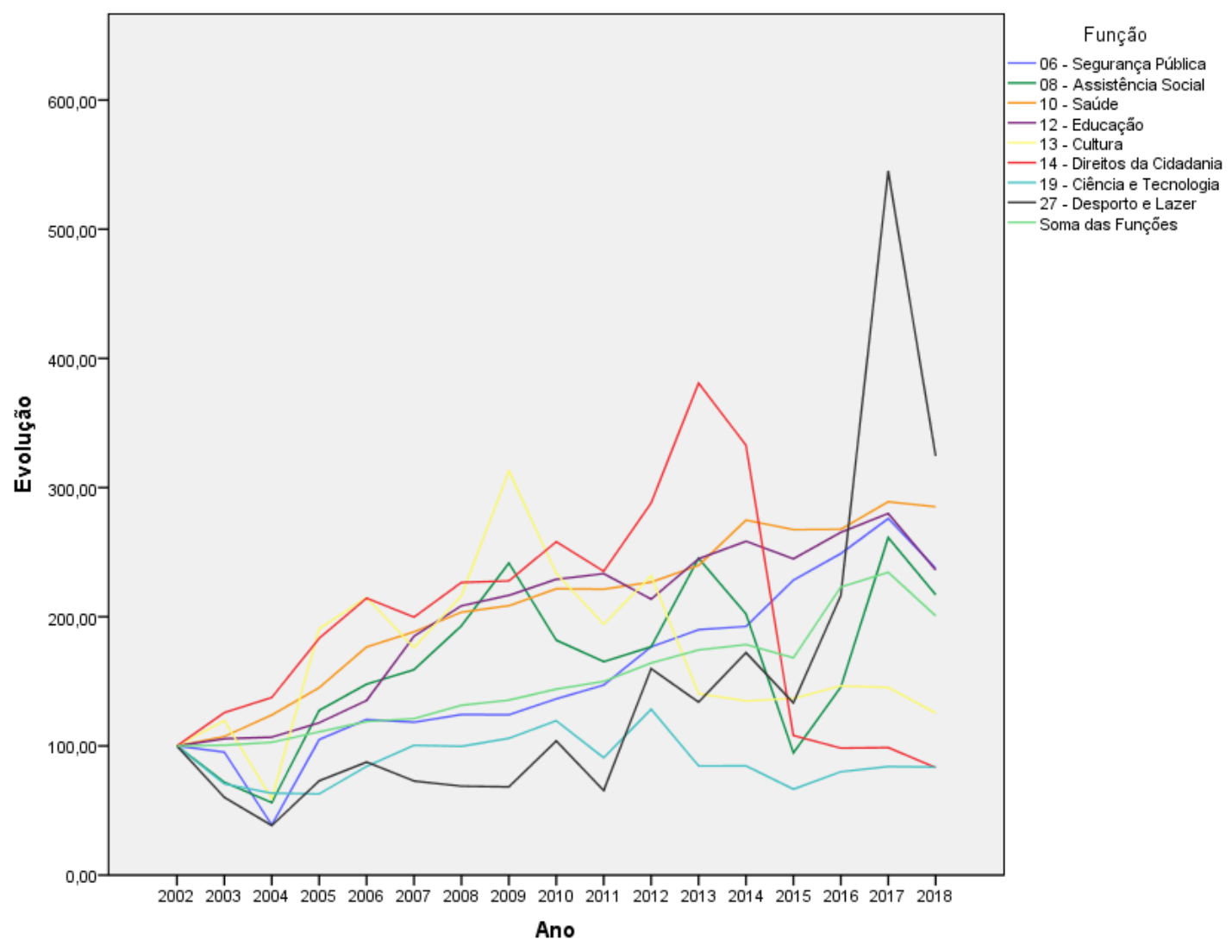

A função "Desporto e Lazer" assim como as áreas de Ciência e Tecnologia, Assistência Social, Cultura e Direitos da Cidadania apresentaram padrões irregulares de investimentos. Já as áreas de Segurança Pública, Saúde e Educação apresentaram uma tendência de aumentos progressivos no decorrer dos anos. Vale observar que Saúde, Educação e Ciência e Tecnologia têm garantias de investimento pelo governo estadual. Saúde e Educação têm percentuais mínimos de investimentos garantidos em lei, sendo $12 \%$ e $25 \%$, respectivamente, dos recursos arrecadados por meio de impostos e transferências. Já Ciência e Tecnologia, de acordo com a Constituição Estadual, o estado deverá destinar anualmente uma parcela não inferior a $2 \%$ de sua receita tributária para o fomento da pesquisa científica e tecnologia (PARANA, 1989). A área da Segurança Pública, especialmente a partir das polícias civis e militares, configura-se como uma responsabilidade do governo estadual, o que resulta no investimento constante para garantir a manutenção destas ações. Deste modo, exceto pela Ciência e Tecnologia, o estabelecimento de percentual mínimo (Saúde e Educação) e/ou a atribuição de competência exclusiva podem ter influenciado na maior estabilidade de investimentos no decorrer dos anos quando comparado com as demais áreas.

Já no caso do esporte, ainda que o seu fomento esteja regulamentado como um dever do poder público, não há garantias de percentuais mínimos, bem como normatizações específicas sobre o grau de intervenção dos entes federativos. Ou seja, tal como indicado por Toledo (2014), a baixa 
institucionalidade do esporte, quando comparado com outras áreas governamentais, pode influenciar no padrão irregular de investimentos na área.

A fragilidade da política esportiva também foi verificada no estado do Piaú. De acordo com Santos e Juchem (2021), as variações e o baixo investimento na função "Desporto e Lazer" apontam para um papel secundário da área frente à outras áreas como Assistência Social e Cultura. Fatores como a inexistência de um sistema nacional, de um órgão de primeiro escalão e de uma agenda organicamente inserida na Assembleia Legislativa atestam a fragilidade institucional da área esportiva (SANTOS; JUCHEM, 2021).

Em relação aos investimentos dentro da função do esporte, exceto pela subfunção "Desporto Comunitário", todas as demais não tiveram constância no decorrer do período, o que indica descontinuidades de investimentos. O movimento de continuidade e descontinuidade também foi observado no Distrito Federal (ATHAYDE; DALMAS, 2018).

No somatório do período, o "Desporto Comunitário" totalizou R\$ 438 milhões (68,2\%), seguido do "Desporto de Rendimento" (R\$ 97 milhões - 15,1\%), demais subfunções (R\$ 82 milhões - 12,7\%) e “Administração Geral” (R\$ 24 milhões - 3,8\%) (TABELA 2).

Tabela 2 - Recursos empenhados nas subfunções da função "Desporto e Lazer" de 2004 a 2018 (valores em R\$)

\begin{tabular}{|c|c|c|c|c|}
\hline Ano & $\begin{array}{c}\text { Desporto } \\
\text { Comunitário }\end{array}$ & $\begin{array}{l}\text { Desporto De } \\
\text { Rendimento }\end{array}$ & $\begin{array}{c}\text { Demais } \\
\text { Subfunções }\end{array}$ & $\begin{array}{c}\text { Administração } \\
\text { Geral }\end{array}$ \\
\hline 2004 & $1.268 .510,99$ & $\mathrm{R} \$ \quad 9.643 .724,12$ & & \\
\hline 2005 & $1.448 .330,71$ & $\mathrm{R} \$ 12.117 .932,13$ & $\mathrm{R} \$ 7.160 .280,97$ & \\
\hline 2006 & $2.407 .794,83$ & $\mathrm{R} \$ 15.084 .942,33$ & $\mathrm{R} \$ 7.359 .014,84$ & \\
\hline 2007 & $767.281,17$ & $\mathrm{R} \$ 12.793 .350,92$ & $\mathrm{R} \$ 7.127 .478,50$ & \\
\hline 2008 & $2.434 .667,22$ & $\mathrm{R} \$ \quad 8.636 .942,10$ & $\mathrm{R} \$ 8.479 .421,13$ & \\
\hline 2009 & $1.538 .669,21$ & $\mathrm{R} \$ \quad 9.803 .172,33$ & $\mathrm{R} \$ 8.057 .979,93$ & \\
\hline 2010 & $1.943 .636,15$ & $\mathrm{R} \$ 19.415 .298,07$ & $\mathrm{R} \$ 8.129 .580,59$ & \\
\hline 2011 & $186.914,12$ & $\mathrm{R} \$ \quad 9.819 .908,43$ & $\mathrm{R} \$ 8.592 .175,26$ & \\
\hline 2012 & $\mathrm{R} \$ \quad 40.475 .504,87$ & & $\mathrm{R} \$ 4.911 .711,80$ & \\
\hline 2013 & $\mathrm{R} \$ \quad 32.825 .735,16$ & & $\mathrm{R} \$ 5.198 .669,47$ & \\
\hline 2014 & $\mathrm{R} \$ \quad 39.068 .086,47$ & & $\mathrm{R} \$ 9.845 .920,89$ & \\
\hline 2015 & $\mathrm{R} \$ 30.631 .688,73$ & & $\mathrm{R} \$ 7.222 .738,27$ & \\
\hline 2016 & $\mathrm{R} \$ \quad 52.078 .908,37$ & & & $\mathrm{R} \$ 9.366 .545,66$ \\
\hline 2017 & $\mathrm{R} \$ 147.138 .713,21$ & & & $\mathrm{R} \$ 7.612 .877,38$ \\
\hline 2018 & $\mathrm{R} \$ \quad 84.418 .403,84$ & & & $\mathrm{R} \$ 7.703 .158,42$ \\
\hline Total & R\$ 438.632.845,06 & R\$ 97.315.270,43 & R\$ 82.084.971,64 & R\$ 24.682.581,46 \\
\hline$\%$ & $68,25 \%$ & $15,14 \%$ & $12,77 \%$ & $3,84 \%$ \\
\hline $\begin{array}{l}\text { Per } \\
\text { Capita }\end{array}$ & $R \$ 42,00$ & R\$ 9,32 & $\mathbf{R} \$ \mathbf{7 , 8 6}$ & $R \$ 2,36$ \\
\hline
\end{tabular}


Vale observar que, de acordo com Milani (2018), a partir de 2012, as ações referentes à subfunção "Desporto de Rendimento" foram redirecionados para a subfunção "Desporto Comunitário. Ou seja, ainda que o "Desporto de Rendimento" tenha zerado seus investimentos a partir de 2013, as ações desta dimensão contaram com recursos alocados na subfunção "Desporto Comunitário". Este remanejamento de recursos, além de impossibilitar a análise adequada das prioridades orçamentárias da política esportiva paranaense, dificulta o controle social dos gastos públicos e contrariam os princípios da transparência e acesso à informação pública.

Em estudos anteriores, as conclusões sobre as prioridades da política esportiva no Paraná divergem. Enquanto Toledo (2014) conclui que a política mantém o padrão histórico de privilegiar a organização de eventos esportivos, Milani (2018) aponta que as atividades priorizadas pelo estado paranaense estão relacionadas a implantação de infraestrutura esportiva.

As prioridades dos investimentos orçamentários dos outros estados brasileiros também apresentam divergências. No Distrito Federal, a política esportiva priorizou os investimentos no esporte de participação (CARNEIRO; MASCARENHAS, 2013). Já em Santa Catarina (FURTADO et al., 2016; QUINAUD; ALMEIDA, 2018; QUINAUD et al., 2018), Minas Gerais (DINIZ; SILVA, 2016) e no Pará (MOREIRA; SILVA, 2020), o gasto priorizou o esporte de rendimento e os eventos esportivos. No Piauí, Santos, Juchem e Maduro (2020) concluíram que o esporte de rendimento não teve centralidade nos investimentos estaduais, e Athayde e Dalmas (2018) apontam que no Distrito Federal houve um maior direcionamento de recursos para a administração da secretaria.

\section{CONSIDERAÇÕES FINAIS}

A análise do comportamento do financiamento orçamentário do estado do Paraná no período de 2002 a 2018 indica que o orçamento esportivo não acompanha as tendências do orçamento estadual e demonstra relativa independência deste. No Paraná, enquanto o orçamento estadual tende a manutenção e a ocorrência de incrementos, o orçamento esportivo é marcado por expressivas oscilações. Ao todo, o governo paranaense destinou R \$ 688 milhões para a função "Desporto e Lazer", o que correspondeu a 0,11\% do orçamento estadual no período de 2002 a 2018.

Entre as subfunções orçamentárias, o "Desporto Comunitário" totalizou o maior volume de recursos e se configurou como a única área que teve constância de investimento. $\mathrm{O}$ "Desporto Comunitário" R\$ 438 milhões (68,2\%), seguido do "Desporto de Rendimento" (R\$ 97 milhões 15,1\%), demais subfunções (R 82 milhões - 12,7\%) e “Administração Geral” (R\$ 24 milhões $3,8 \%$ ). Todavia, vale observar que os investimentos estaduais para a subfunção "Desporto de 
Rendimento" foram redirecionados para o "Desporto Comunitário", o que impossibilita a análise acurada das prioridades que foram tomadas pelo governo estadual durante o período.

Em comparação com outras áreas de atuação governamental, o índice de investimento esportivo paranaense, exceto por 2005 e 2006, esteve abaixo de todas as áreas analisadas até 2011. Mudanças políticas e administrativas ocorridas a partir de 2011 podem estar relacionados a um acréscimo na representatividade da área em relação ao orçamento geral e em relação a outras áreas como Cultura, Direitos da Cidadania e Assistência Social.

Apesar do acréscimo, o orçamento esportivo paranaense apresenta expressivas oscilações e assemelha-se às particularidades estaduais e federativas observadas por estudos anteriores. A não vinculação e obrigatoriedade de investimentos no esporte, ausência de atribuições dos entes federativos e baixa institucionalidade da política esportiva, o comportamento cíclico eleitoral de investimentos, e o grande volume de emendas parlamentares no orçamento esportivo podem se configurar como fatores que provocam um padrão irregular de investimentos na função "Desporto e Lazer" e, consequentemente, fragilizam o acesso ao esporte. Os fatores, todavia, que impactam no comportamento dos gastos em esporte e lazer pelos entes federativos precisam ser elucidados pela literatura. Seja no âmbito local, regional ou federal, a garantia de recursos, bem como a constância de investimentos são elementos fundamentais para a consecução das políticas esportivas e, consequentemente, do acesso ao esporte enquanto um direito de cada um.

\section{REFERÊNCIAS}

ARRETCHE, Marta. Federalismo e políticas sociais no Brasil: problemas de coordenação e autonomia. São Paulo em Perspectiva, São Paulo, v. 18, n. 2, p. 17-26, 2004.

ASSIS, Luis Gustavo Bambini de. Processo legislativo e orçamento público: a função de controle do parlamento. 2009. Tese (Doutorado em Direito) - Faculdade de Direito, Universidade de São Paulo, São Paulo, 2009.

ATHAYDE, Pedro Fernando Avalone; DALMAS, Leandro Casarin. Políticas de esporte do Distrito Federal: uma análise sobre a legislação, gestão e o financiamento entre os anos de 2008 a 2014. R. bras. Ci. e Mov, v. 26, n. 2 , p. $113-128,2018$.

ATHAYDE, P. F. A; MASCARENHAS, F.; SALVADOR, E. Primeiras aproximações de uma análise do financiamento da política nacional de esporte e lazer no governo Lula. Rev. Bras. Ciênc. Esporte, v. 37, n. 1, p. 2-10, 2015.

BOTELHO, Isaura. Dimensões da Cultura e Políticas Públicas. São Paulo em Perspectiva, n. 15, p.73-83, 2001.

BRASIL. Lei nº 9.615, de 24 de março de 1998. Diário Oficial da União: Brasília, DF, 24 mar. 1998.

BRASIL. Ministério do Esporte. Esporte, lazer e desenvolvimento humano - texto final da I Conferência Nacional do Esporte. Brasília, 2004. 
BRASIL. Ministério do Esporte. II Conferência Nacional do Esporte - documento final. Brasília, 2006.

BRASIL. Ministério do Esporte. III Conferência Nacional do Esporte. Brasília, 2010.

BRASIL. Senado Federal. Projeto de Lei do Senado n 67, de 2017. Institui a Lei Geral do Esporte. 2017.

BRASIL. Lei n 13.756, de 12 de dezembro de 2018. Diário Oficial da União, Brasília, DF, 12 dez. 2018.

CARNEIRO, Fernando Henrique Silva; MASCARENHAS, Fernando. O direito ao esporte no Distrito Federal: entre o planejado e o executado. In: Congresso Brasileiro de Ciências do Esporte / Congresso Internacional de Ciências do Esporte, 18/5, 2013, Brasília. Anais eletrônicos... Brasília: 2013.

Carneiro, Fernando Henrique Silva. ATHAYDE, Pedro Fernando Avalone. MASCARENHAS, Fernando. A participação dos entes federados no financiamento ao esporte e lazer no Brasil. PODIUM Sport, Leisure and Tourism Review, São Paulo, v. 10, n. 1, 163-186, jan./abr., 2021.

CASTRO, S. B. E. Políticas públicas para o esporte e lazer e o ciclo orçamentário brasileiro (20042011): prioridades e distribuição de recursos durante os processos de elaboração e execução orçamentária. 2016. Tese (Doutorado em Educação Física) -Universidade Federal do Paraná, Curitiba, 2016.

DINIZ, Rafael Silva; SILVA, Luciano Pereira da. O ICMS esportivo e o financiamento das políticas municipais de esporte em Minas Gerais. Movimento, Porto Alegre, v. 22, n. 4, 1223-1236, out./dez. de 2016

FERNANDES, Cleiton das Chagas. Emendas parlamentares: orçamento do Distrito Federal. 2012. Monografia (especialização) - Câmara dos Deputados, Distrito Federal, 2012.

FONSECA, Guilherme ParentoniSenra et al. Emendas parlamentares: a relação entre o Executivo e o Legislativo em Minas Gerais. In: Congresso Consad de Gestão Pública, VIII. Anais... 2015.

FURTADO, Sabrina et al. O financiamento do esporte em Santa Catarina: o caso do FUNDESPORTE nos anos de 2011 e 2012. Motrivivência, v. 28, n. 47, p. 145-159, mai. 2016.

IBGE. Instituto Brasileiro de Geografia e Estatística. Sistema nacional de índices de preços ao consumidor. 2017.

MENEZES, David Curtinaz. PEDERIVA, João Henrique. Orçamento Impositivo: Elementos para Discussão. Administração Pública E Gestão Social, v. 7, n. 4, 178-186, 2015.

MILANI, Fernanda Gimenez. Políticas públicas estaduais de esporte: uma análise a partir do planejamento e execução do orçamento público. 2018. Dissertação (Mestrado em Educação Física) - Universidade Estadual de Maringá, Maringá, 2018.

MOREIRA, Fátima de Souza. SILVA, Luciano Pereira da. A política de esporte no estado do Pará no período de 2012 a 2013. Motrivivência, v. 32, n. 63, p. 01-21, julho/dezembro 2020.

ORAIS, Rodrigo Octávio et al. Ciclos políticos eleitorais e investimentos das administrações públicas no Brasil. Texto para Discussão, No. 1999. Instituto de Pesquisa Econômica Aplicada (IPEA): Brasília, 2014.

PARANÁ. Constituição do Estado do Paraná. Diário Oficial do Estado: Curitiba, PR. 05 de outubro de 1989.1989.

PARANÁ. Decreto nº 702, 28/04/95. Diário Oficial do Estado: Curitiba, PR, 1995.

PARANÁ. Lei nº 15.264, 12/09/2006.Diário Oficial do Estado: Curitiba, PR, 2006. 
PARANÁ. Lei nº17.014, 16/11/2011.Diário Oficial do Estado: Curitiba, PR, 2011.

PARANÁ. Decreto n8.560, 20/12/2017. Diário Oficial do Estado: Curitiba, PR, 2017.

PARANÁ. Política de Esportes do Paraná. Lei Estadual de Incentivo ao Esporte - Proesprote. Curitiba, 2018.

QUINAUD, Ricardo Teixeira et al. Demandas e distribuição de recursos do fundo estadual de esporte de Santa Catarina: análise das propostas esportivas submetidas de 2007 a 2014. Rev. Bras. Ciênc. Esporte, v 41, n. 3, p. 241-247, jul./set. 2019.

QUINAUD, Ricardo Teixeira; ALMEIDA, Bárbara Schausteck de. Financiamento público no esporte: os repasses do Estado de Santa Catarina para projetos na Mesorregião Grande Florianópolis (2007-2014).

Pensar a Prática, Goiânia, v. 21, n. 2, p. 338-352, abr./jun. 2018.

SANTOS, Edmilson Santos dos; CARVALHO, Maria José; SOUSA, Marisa. Participation of the federation units in the investment of sports and leisure policies in Brazil. Licere, Belo Horizonte, v.23, n.4, dez/2020.

SANTOS, Edmilson Santos dos; JUCHEM, Luciano; MADURO, Luiz Alcides Ramires. Expenditure on sports and leisure by the government of the state of Piauí. J. Phys. Educ. v. 32, e3202, 2021.

SANTOS, Edmilson Santos dos; MENDES, Alessandra Dias. Níveis de adesão ao gasto público na função Desporto e Lazer por parte dos municípios brasileiros. Pensar a Prática, v. 23, e54542, 2020.

SILVA, Temistocles Damasceno. O planejamento e a estrutura financeira das políticas públicas de lazer no estado da Bahia. Coleção Pesquisa em Educação Física, v. 14, n. 4, 2015.

SOUZA, Simone de. XAVIER, Rodrigo Silveira. ARRUDA, Alessandro Gustavo Souza. Orçamento impositivo e governança pública: análise da execução das emendas impositivas no âmbito federal. In.: ENCONTRO INTERNACIONAL DE GESTÃO, DESENVOLVIMENTO E INOVAÇÃO, IV, 2020. Anais... 2020.

TOLEDO, Renata Maria. As políticas públicas e o direito "social" ao esporte: uma análise a partir do Estado do Paraná (1995-2010). 2014. Tese (Doutorado em Sociologia) - Universidade Federal do Paraná, Curitiba, 2014.

\section{NOTAS DE AUTOR}

AGRADECIMENTOS - Não se aplica.

CONTRIBUIÇÃO DE AUTORIA - Não se aplica.

FINANCIAMENTO

Esta pesquisa contou com o apoio financeiro do Programa Nacional de Pós-doutorado (PNPD/CAPES) e do Instituto de Pesquisa Inteligência Esportiva (IPIE/UFPR).

CONSENTIMENTO DE USO DE IMAGEM - Não se aplica.

APROVAÇÃO DE COMITÊ DE ÉTICA EM PESQUISA - Não se aplica.

CONFLITO DE INTERESSES - Os autores declaram não haver conflito de interesses. LICENÇA DE USO 
Os autores cedem à Motrivivência - ISSN 2175-8042 os direitos exclusivos de primeira publicação, com o trabalho simultaneamente licenciado sob a Licença Creative Commons Attribution Non-Comercial ShareAlike (CC BY-NC SA) 4.0 International. Esta licença permite que terceiros remixem, adaptem e criem a partir do trabalho publicado, desde que para fins não comerciais, atribuindo o devido crédito de autoria e publicação inicial neste periódico desde que adotem a mesma licença, compartilhar igual. Os autores têm autorização para assumir contratos adicionais separadamente, para distribuição não exclusiva da versão do trabalho publicada neste periódico (ex.: publicar em repositório institucional, em site pessoal, publicar uma tradução, ou como capítulo de livro), com reconhecimento de autoria e publicação inicial neste periódico, desde que para fins não comerciais e compartilhar com a mesma licença.

\section{PUBLISHER}

Universidade Federal de Santa Catarina. Programa de Pós-Graduação em Educação Física. LaboMídia - Laboratório e Observatório da Mídia Esportiva. Publicado no Portal de Periódicos UFSC. As ideias expressadas neste artigo são de responsabilidade de seus autores, não

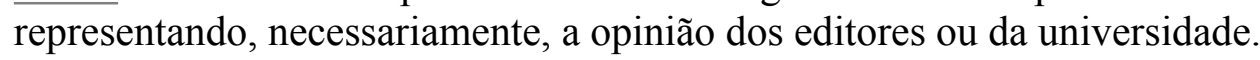

\section{EDITORES}

Mauricio Roberto da Silva, Giovani De Lorenzi Pires, Rogério Santos Pereira.

\section{EDITOR DE SEÇÃO}

Juliano Silveira.

\section{REVISÃO DO MANUSCRITO E METADADOS}

João Caetano Prates Rocha; Keli Barreto Santos.

\section{HISTÓRICO}

Recebido em: 09 de junho de 2021.

Aprovado em: 02 de setembro de 2021. 